\title{
Bolivarianismo en la encrucijada. Análisis de la ascensión y crisis del chavismo desde sus conceptos
}

\author{
Fabricio Pereira da Silva \\ UNIRIO, Rio de Janeiro, Brasil \\ Email: fabriciopereira31@gmail.com
}

\begin{abstract}
Resumen: El artículo analizala ascensión y crisis del chavismo a partir de sus ideas y principales conceptos políticos. Asume centralidad la historia reciente del desarrollo y apropiación oficial del concepto de "bolivarianismo". Adicionalmente, se presenta cómo el concepto secundario de "socialismo del siglo XXI” emergió en el contexto venezolano, en tensa relación con la anterior noción de bolivarianismo; y cómo la noción de democracia fue articulada de manera muy particular con esos conceptos. Se propone como hipótesis que esa apropiación forma parte de una tradición ya larga de las izquierdas en las periferias, que buscan nacionalizarse y presentarse como parte de una historia nacional que para ellas tendría en su origen pretensos elementos igualitaristas, progresistas, revolucionarios. Esas allegadas tradiciones enmarcadas en el pasado local, en lo "propio", podrían según ellas servir de base para la proyección de una sociedad distinta en el futuro.
\end{abstract}

Palabrasclave: Bolivarianismo, chavismo, Venezuela, pensamiento político latinoamericano, conceptos políticos

\section{Bolivarianismo at the cross roads. Analysis of therise and crisis of chavismo from its own concepts}

\begin{abstract}
The article examines the rise and crisis of chavismo from its ideas and main political concepts. The recent history of the development and official appropriation of the concept of "Bolivarianism" takes a central place. In addition, it presents how the secondary concept of "21st century socialism" emerged in the Venezuelan context, in a tense relationship with the previous notion of Bolivarianism; and how the notion of democracy was articulated in a very particular way with those concepts. It is proposed as a hypothesis that this appropriation is part of an already long tradition of left-wing groups in the peripheries, which seek to nationalize and present themselves as part of a national history that for them would have in its origin pretentious egalitarian, progressive, and revolutionary elements. These close traditions framed in the local past, in the "own", could according to them serve as a basis for the projection of a different society in the future.
\end{abstract}

Keywords: Bolivarianism, chavismo, Venezuela, latin-American political thought, political concepts 


\section{Bolivarianismo na encruzilhada. Análise da ascensão e crise do chavismo a partir de seus conceitos}

Resumo: O artigo analisa a ascensão e crise do chavismo a partir de suas ideias e principais conceitos políticos. Assume centralidade a história recente do desenvolvimento e apropriação oficial do conceito de "bolivarianismo". Adicionalmente, se apresenta como o conceito secundário de "socialismo do século XXI" emergiu no contexto venezuelano, em tensa relação com a anterior noção de bolivarianismo; e como a noção de democracia foi articulada de maneira muito particular com esses conceitos. Se propõe como hipótese que essa apropriação forma parte de uma tradição já longa das esquerdas nas periferias, que buscam se nacionalizar e se apresentar como parte de uma história nacional que para elas teria em sua origem pretensos elementos igualitários, progressistas, revolucionários. Essas alegadas tradições enraizadas no passado local, no "próprio”, poderiam segundo elas servir de base para a projeção de uma sociedade distinta no futuro.

Palavras-chave: Bolivarianismo, chavismo, Venezuela, pensamento político latino-americano, conceitos políticos

$* * *$

\section{Introducción}

El presente artículo hace un análisis del proceso de ascensión y crisis del chavismo desde un abordajede sus ideas y principales conceptos políticos. De esa manera, asume centralidad la historia reciente del desarrollo y apropiación oficial del concepto de "bolivarianismo". Se sustenta que esa apropiación forma parte de una problemática más larga y general de las izquierdas en las periferias, que buscan nacionalizarse y presentarse como parte de una historia nacional que para ellas tendría en su origen pretensos elementos igualitaristas, progresistas, revolucionarios. Esas allegadas tradiciones enmarcadas en el pasado local, en lo “propio”, podrían según ellas servir de base para la proyección de una organización social distinta en el futuro. Adicionalmente, se presenta cómo el concepto de "socialismo del siglo XXI” emergió en el contexto venezolano, en (algo) tensa relación con la más establecidanoción de bolivarianismo; y cómo la noción de democracia fue articulada de manera muy particular con aquellos dos conceptos.

Desde las especificidades del desarrollo de los conceptos de bolivarianismo, socialismo del siglo XXI y democracia por el chavismo (y cómo ellos se articularon), se espera contribuir al debate más general de la historia de las ideas en la periferia global, particularmente de cómo las izquierdas de la periferia adaptan ideas producidas en el centro y presentadas como "universales" (como socialismo y democracia) mientras buscan desarrollar versiones propias de ideas locales (como bolivarianismo). Eso genera tensiones, y la producción de ideas desde el chavismo es un buen caso de estudio para entender esas tensiones. De ese modo, más allá del interese venezolano y latinoamericano de estudiar las ideas del chavismo y particularmente su (re)interpretación del bolivarianismo, es relevante in- 
vestigarlo como un rico ejemplo de las tensiones entre“universal” y "particular” en el pensamiento de la periferia, y la función del pasado local en los proyectos de futuro. La hipótesis es que esas dos complejas y algo contradictorias relaciones se presentan a todo momento en el accionar ideológico del chavismo, como (espero) se constatará al largo del análisis. El artículo se estructura de la siguiente forma. En la primera parte, se presenta el marco teórico y metodológico.

En la segunda parte, el bolivarianismo y particularmente su desarrollo reciente son analizados, como un elemento esencial de la hegemonía chavista de casi dos décadas. En la tercera parte, se hace una discusión de la noción de socialismo del siglo XXI, en la medida que se presenta en dado momento como un nuevo significante para el chavismo. En la cuarta parte, se presenta la particular articulación de esas ideas con la noción de democracia.

En la Conclusión, se hace un debate más teórico y general que busca poner el caso venezolano en perspectiva global (más precisamente como parte de la periferia global), articulado a una agenda investigativa en la periferia y desde la periferia de las ideas de izquierda y de la teoría crítica.

\section{Marco teórico-metodológico}

Ese artículo se adscribe a un marco teórico ubicado en la historia y la sociología de las ideas, a partir de una perspectiva que reivindica las teorías críticas de una forma "ecuménica” (sin la filiación explícita a un autor o escuela específica). Se propone analizar ideas que de un modo general asumen una posición subalterna en los debates teóricos, y con eso propiciar el "diálogo horizontal entre conocimientos" diversos que Boaventura de Sousa Santos (2010) llamade “ecología de saberes”, en contrapunto al "monocultivo de la ciencia moderna”. Se entiende esas ideas como producidas en la periferia global. Ellas son producto de intelectuales que asumen una "consciencia de ser periferia”, como desarrollado por Eduardo Devés-Valdés (2017). Esa “consciencia” permite caracterizar sus formulaciones como parte de un pensamiento periférico, entendido como interiorización reflexiva en el campo de las ideas de un fenómeno más general que asume materialidad en el sistema mundial capitalista y en las relaciones internacionales. Es una lógica e inserción que se retroalimentan, y que marcan la producción de conocimiento y el desarrollo de las ideas, provocando situaciones como: la centralidad de la recepción de ideas originadas en los países centrales, el dilema entre la valoración de tradiciones e identidades locales o la "modernización” a partir de modelos externos, y las reflexiones sobre el papel de sus países y regiones en el mundo (sin ya son “occidentales”, sin son pasibles de “occidentalización” o si están condenados a buscar un lugar y una inserción internacionalpropios).

La Revolución Bolivariana se presenta como una propuesta de “refundación” (Pereira da Silva, 2011), y en ese sentido necesita sustentar- 
se en el pasado nacional - aunque sea en un pasado reinterpretado. De ese modo son procesos de invención y reinvención de tradiciones,en el sentido definido por Eric Hobsbawm y Terence Ranger (2012), procesos que dependen en buena medida de la agencia individual (en especial de individuos en posición de liderazgo político como Hugo Chávez) y colectiva, aunque dentro de límites estructurales. Un punto nodal es definir hasta qué punto la creatividad por parte de sujetos individuales y colectivos puede expresarse en la producción de ideas. A través de la noción de "ideología”, las ideas asumieron desde versiones más ortodoxas del marxismo un papel secundario, de variable dependiente de lo económico, y por veces hasta un sentido de falsificación, distorsión de la realidad por parte de la clase dominante.

Sin embargo, autores marxistas como Antonio Gramsci (2001) se alejaron en cierta medida de esa limitación, al defender la centralidad de la lucha por la hegemonía en sociedades (que él llamaba) “occidentalizadas” que exigirían la estrategia de ocupación y lucha por cada espacio (la metáfora de la “guerra de posición”); y el papel no sólo de la coerción, pero principalmente del consenso por parte de un Estado ahora “ampliado”. De esas premisas derivan la relevancia del desarrollo de nuevas formas éticas que sean “orgánicas” y “psicológicamente válidas”, y el papel del intelectual (y del partido como el "intelectual colectivo”, el "Moderno Príncipe”). Pero no fue exactamente Gramsci quien se alejó de la tesis de la determinación económica (eso lo haría alejarse del marxismo), pero algunos de sus intérpretes como Ernesto Laclau (2009), que enfatizó la necesidad de construcción hegemónica y defendió la centralidad de lo político.

Lo que es más importante en esos procesos de reinvención (como ocurre con el bolivarianismo) nos es evaluar la "validad" o la "coherencia" de las ideas, pero como esas narrativas ofrecen legitimidad, cohesión y sentido a la construcción de una nueva hegemonía. Se debe enfatizar que al escoger categorías analíticas como “adaptación”, “hibridación”, “invención”, “interpretación”, “creación”, se reconoce el peso de la creatividad en el desarrollo y expresión de las formaciones sociales. Sin embargo, esas creaciones no son evidentemente ilimitadas. Considero que "significantes vacíos” (en términos laclaunianos) no pueden ser constituidos a partir de cualquier “significado”. Las articulaciones de las diferencias en la sociedad se pueden hacer bajo ciertos límites materiales.Y fue desde ese delicado equilibrio que ideas como "bolivarianismo", "socialismo del siglo XXI" y “democracia participativa y protagónica” sirvieron por un cierto periodo de significantes para el establecimiento de una nueva hegemonía - ahora en profunda crisis.

El periodo estudiado en el artículo empieza con la elección presidencial de 1998 y termina con la muerte de Chávez en 2013. Ese periodo puede ser entendido como un recorte que permite abordar la ascensión, desarrollo y el comienzo de la crisis del chavismo. Se trabaja con base en un largo levantamiento de programas partidarios o de gobierno y discursos de Chávez, y de literatura secundaria - realizado por el autor en los últimos diez 
años en seguidas investigaciones sobre Venezuela ytrabajos de campo.A partir de esas fuentes,se busca delimitar, determinar los sentidos y hacer una historia de los tres conceptos, para a partir de ellos abordar el chavismo desde una perspectiva que se espera novedosa.

\section{El Bolivarianismo y su relevancia en la constitución del chavismo}

El bolivarianismo se presenta como una tradición antes que todo nacional, notablemente venezolana. Para entenderlo, se debe remeter al fenómeno de construcción de la identidad del país a partir de la figura del "Libertador” y su "gesta” independentista. La obra de Simón Bolívar, no muy sistemática y organizada, producida en el largo proceso de las luchas de independencia y de los intentos de organizar el nuevo país (que en principio no era Venezuela, pero la Gran Colombia mientras primer paso haciauna confederación de la "América Meridional”), se presta a considerables (re)interpretaciones. De hecho, desde poco antes de su muerte en 1830, Bolívar empezó a servir de inspiración en Venezuela a un proceso de legitimación de sus elites, que el historiador Germán Carrera Damas (2013) llamó en sus trabajos el "culto a Bolívar". El culto surge de la necesidad compartida por la clase dominante venezolana en restablecer el dominio y la estructura de la sociedad, legitimándose "a la sombra del Libertador” (Seabra, Pereira da Silva, 2012). Sin embargo, Carrera Damas señaló más allá de ese proceso de invención oficial el surgimiento de un culto "popular" a Bolívar, en clave progresista, con contenido de justicia social. "El pueblo no se dedicó al culto del Bolívar constructor del orden, y sí del Bolívar libertador de los esclavos y jefe de los ejércitos populares” (Figueiredo, 2013, p. 107). Y desde entonces aguardó en sentido mesiánico por el surgimiento de un nuevo Bolívar. Carrera Damas denomina los dos procesos respectivamente de culto a Bolívar "para el pueblo” y “del pueblo”.

Es precisamente a ese fenómeno en clave popular y progresista que las izquierdas venezolanas (intelectuales y grupos políticos) recurrieron en su proceso de nacionalización, empezando por lo menos desde los años 1960 mientras se alejaban de la ortodoxia soviética y del llamado "socialismo real" a producir - entre otras apropiaciones del ideario de Bolívar por fuerzas políticas de distintos cuadrantes ideológicos - un bolivarianismo desde la izquierda (y un buen ejemplo de eso es la obra de Francisco Pidival de 1977, que presenta un Bolívar revolucionario y precursor del antiimperialismo). Entonces, más allá del "culto a Bolívar" (pero basado en él), empezó a manifestarse un "bolivarianismo" desde la izquierda. Ese ideario puede ser definido por puntos que son reinterpretados como clave en el pensamiento de Bolívar, que tendrían todavía validad contemporánea bajo alguna adaptación: la defensa de una independencia plena, la insistencia en el camino "revolucionario", las advertencias sobre el peligro del expansionismo de los EUA (lo que sería una anticipación del antiimperialismo). El bolivarianismo se presenta como un rescate y conti- 
nuidad del proyecto emancipatorio venezolano, que sería anti oligárquico y antiimperialista en su origen, para la realización de una "segunda emancipación”.

Poco más tarde siguieron ese camino, con considerable ímpeto, Hugo Chávez, su Movimiento Bolivariano Revolucionario 200 (MBR-200) y después su Movimiento V República (MVR). La organización sucedánea, el Partido Socialista Unido de Venezuela (PSUV), heredaría el bolivarianismo, pero en clave un tanto distinta, como se verá.La herencia bolivariana fue entendida por Chávez y sus partidarios a partir de tres ejes: independencia nacional (necesidad de una "segunda independencia" antiimperialista y anti-oligárquica), soberanía popular (búsqueda de una "democracia verdadera" basada en una expresión de la "voluntad general") y justicia social (rescate del "bien común”, de la igualdad). Hay evidentemente un tanto de Jean-Jacques Rousseau en todo eso, una presencia que ya era central en el pensamiento de Bolívar.

El método para hacer de todo eso realidad fue el revolucionario: sea por medio del intento de golpe en 1992 (“insurrección armada” según el chavismo), sea la "revolución por el voto" o "revolución democrática” desde 1998 (la Revolución Bolivariana). En ese sentido, Bolívar fue (re)interpretado como un revolucionario que según Chávez en su Libro Azul (el texto fundacional del pensamiento de Chávez y del MBR-200)tenía una "sólida convicción acerca del proceso revolucionario como un paso necesario para lograr las transformaciones de la vieja sociedad", era un “actor revolucionario" (Chávez, 2007, p. 51) - lo que es una evidente transposición al accionar político de principios del siglo XIX de términos, fraseologías y formas de pensar contemporáneas.

De ese modo, "siguiendo la distinción que Carrera Damas hace entre culto cívico estatal y culto popular, lo que Chávez pretendía (...) era volver 'oficial' la segunda vertiente, transformadora y plena de potencial revolucionario” (Figueiredo, 2013, p. 76). La segunda vertiente fue efectivamente superando la primera en los últimos años (y parcialmente mezclándose a ella).El bolivarianismo constituye la base del sistema ideológico elaborado por Chávez y su movimiento, que agrega además elementos del pensamiento de Simón Rodríguez y deEzequiel Zamora (que participó de la Guerra Federal de mediados del siglo XIX). Rodríguez (o "Samuel Robinson”) fue el tutor de Bolívar.La influencia robinsoniana en la Revolución Bolivariana es más grande de lo que en general se considera. Por ejemplo, en el Libro Azul Rodríguez recibe casi tanta centralidad cuanto Bolívar, en especial por su énfasis en la necesidad de "ideas e instituciones originales para un pueblo original”. Zamora fue un liberal radical, un líder federalista y anti oligárquico que participó de la Guerra Federal de 1859 a $1863^{1}$. Los tres forman el Árbol de las Tres Raíces o Sistema EBR (Ezequiel, Bolívar y Robinson) en lo cual el MBR-200 y el MVR se sustentaron. Ese pensamiento:

articula el ideal libertario, de cohesión y movilización de Bolívar; la interpretación que hacen de Rodríguez respecto a la importancia que 
éste le adjudicó a la economía social, a la educación popular, y a las ideas ‘tierra y hombres libres', 'elección popular' y 'horror a la oligarquía’ de Ezequiel Zamora en la guerra federal (1859-1863), cuya síntesis consideran la ideología bolivariana. Chávez acepta que esa síntesis es compleja y todavía inconclusa, pero rechaza hacer proyectos ideológicos, los considera una trampa porque la ideología que acoge es la del pueblo y ella sólo se construye recogiendo el pensamiento popular, y esa labor es compleja porque el pensamiento popular es difuso. (Pereira Almao, 2003, p. 589).

Bolívar y particularmente Rodríguez insistían en la originalidad del continente americano y del llamado "hombre americano". Rodríguez formula la conocida consigna “o inventamos o erramos" (mencionada repetidamente por Chávez en sus discursos) en su libro Sociedades Americanas, de 1842: “¿Dónde iremos a buscar modelos? La América Española es original. Originales han de ser sus instituciones y su gobierno. Y originales los medios de fundar uno y otro. O inventamos o erramos” (Rodríguez, 2004, p. 138).

Sin embargo, el énfasis puesto en la invención, el bolivarianismo como se mencionó es anterior a Chávez y su movimiento - y más antiguo es el culto a Bolívar, tratándose de hecho de una larga tradición. De esa manera, los dos van más allá del liderazgo de Chávez, y del “chavismo” derivado de él. Una vertiente específica del bolivarianismo (de la izquierda nacional venezolana) fue apropiada por el líder, forneciendo nombre y substancia a la Revolución Bolivariana, en un esfuerzo de demostrar su pluralidad y sus raíces históricas. Más que eso, de defender su necesidad y urgencia histórica, su originalidad y creatividad:
Afirmar que una revolución tiene carácter 'bolivariano' es afirmar el carácter original de esa revolución. Es afirmar que ella no es copia de fórmulas importadas, pero creación nueva a partir de una historia y realidad propias. Al buscar en Bolívar y en los demás líderes de la Independencia su fuente teórica y su simbología, los bolivarianos reafirman la necesidad de producir soluciones latinoamericanas para los problemas latinoamericanos y demuestran que existe de hecho receptividad a ese discurso (Figueiredo, 2013, p. 126).

Eso seguramente sobrevivirá a la muerte de Chávez en 2013, generando posiblemente una mezcla entre bolivarianismo y chavismo, una asociación de dos mitos. Se puede sugerir de ese modo que el bolivarianismo se constituyó como un significante de suceso (para remeter a términos de Ernesto Laclau), pues asumió el significado de proyecto e ideales que fornecen un sentido histórico a lo que es el "pueblo" venezolano y su destino manifiesto, en torno del cual se condensó de hecho una gran parte de los venezolanos en estos años. Será necesario más tiempo para evaluar si el significante "chavismo" podrá actuar en el mismo sentido, pero es probable que sí. Pedro Zúquete (2008) analizó lo que nombró “política misionaria” de Chávez, observando que su liderazgo estuvo asociado arquetípicamente a ejemplaridad moral, asociación con el pueblo, disposi- 
ción al martirio, significación histórica como un grande hombre, un héroe, una figura excepcional. En proceso de mitificación ya en vida, el Chávez post muerte puede, asociado ya con imágenes y símbolos bolivarianos y cristianos, asumirse plenamente mientras un mártir de su pueblo - lo que se puede incluso profundizar como estrategia de sobrevivencia en ese momento crítico del proyecto y del gobierno.

Se puede mencionar que en otros países latinoamericanos donde gobiernos a la izquierda fueron formados en los últimos años las referencias a Bolívar, mucho más puntuales, son hechas en un sentido distinto: sirven de inspiración y justificativa no tanto para la intervención en la política nacional, pero para proyectos latinoamericanistas de integración. Ese elemento latinoamericanista del bolivarianismo tampoco es nuevo, y puede ser mapeado en el pensamiento político y social latinoamericano, presente en autores como Francisco Bilbao, José Martí, José Enrique Rodó, Víctor Raúl Haya de la Torre y muchos otros. Esa vertiente fue por veces nombrada "bolivarismo", en general en contraposición a un "monroísmo" (referencia a la Doctrina Monroe formulada en 1823 por James Monroe y resumida en la consigna “América para los americanos”, la base del panamericanismo). Esa dicotomía fue alimentada entre otros por José Vasconcelos en su obra “Bolivarismo y Monroísmo” (1934). A nivel regional, Bolívar era y es entendido como un marco fundador del latinoamericanismo, no como un "héroe nacional" o inspirador de un cuerpo coherente de ideas republicanas, igualitarias y progresistas ${ }^{2}$.

Ese elemento latinoamericanista del Bolivarianismo evidentemente se hace presente también en el chavismo y en su Bolívar, pero este Bolívar es "venezolano". Eso no considerando que la idea misma de Venezuela no era determinante en su pensamiento, que concebía patria en dimensiones más continentales: en unos momentos hablaba de "América", en otros de “América Meridional” (nunca de "América Latina”, noción por entonces todavía no inventada). Esto se observa, por ejemplo, en la "Contestación de un americano meridional a un caballero de esta Isla”, más conocida como “Carta de Jamaica”, de 1815. Pero el culto a Bolívar generado en Venezuela desde entonces tendría por supuesto que producir una nacionalización del mito. Sin embargo, para el bolivarianismo en la versión chavista, el Bolívar latinoamericanista es indisociable del Bolívar republicano y progresista - lo que hace sentido si volvemos a su pensamiento político, pues para él la unión de los americanos a través de una confederación era en cierto sentido el método, el corolario para la realización y consolidación de sus propuestas.

\section{El Socialismo del Siglo XXI y su inserción en el debate}

La idea de nuevos socialismos agrega según Biardeau (2009a) dos sentidos semánticos complementarios: la necesidad de criticar y alejarse del llamado "socialismo realmente existente" o "del siglo XX" (entendido como estatista, centralizador, autoritario); y también de (re)construcción de 
un socialismo a la altura de los desafíos puesto por la contemporaneidad. Yo agregaría un tercer sentido, funcional a los dos anteriores: lo de originalidad, o sea, de nacionalización o latinoamericanización. En ese sentido, los nuevos socialismos latinoamericanos son también socialismos autóctonos, apropiados a la realidad que quieren cambiar. Por otro lado, se insiste en el significante "socialismo", preservándose un elemento de tradición pretensamente "universal”, pero asociado en esos casos a elementos de las tradiciones locales.

La propuesta de adaptar cronológica y geográficamente el socialismo no es novedad en América Latina: basta pensar en el "socialismo indoamericano” de José Carlos Mariátegui; en la influencia marxista en las primeras obras de Haya de la Torre; en los elementos nacionales en la Revolución Cubana y su reapropiación de la figura de José Martí; o en la "Vía Chilena al Socialismo" de Salvador Allende. Es una reedición de socialismos locales lo que se presenta en ese principio de siglo XXI en formulaciones como la del "socialismo del siglo XXI", probablemente la más conocida entre las más recientes versiones de socialismo, y muy presente en la Revolución Bolivariana desde 2005. Por algún tiempo se apuntó el teórico alemán-mexicano Heinz DieterichSteffan como el creador del concepto. El autor formuló una versión elaborada de lo que podría ser un socialismo para el siglo XXI, por medio de una nueva ética basada en la sustitución del valor de cambio por el valor de uso en la vida material; de los avances del pensamiento científico y tecnológico que permitirían la planificación de sociedades complejas; y de la autodeterminación originada de la democracia participativa (Dieterich, 2002; Dieterich, Franco, 2012).

Sin embargo, acompaño a Javier Biardeau (2009a) en dos observaciones. Primero: "no existe un foco exclusivo de enunciación del nuevo socialismo” (p. 347) - el autor menciona, más allá de Dieterich, la presencia de otros teóricos que propusieron simultáneamente un "nuevo socialismo"u“"socialismo del siglo XXI": Alexander Buzgalin, Paul Cockshott y AllinCottrell, IstvánMészáros, Michel Lebowitz y otros. Segundo, entendiendo el viraje socialista bolivariano más como una ventana de oportunidad que exigió teorización que como una profunda elaboración teórica que hizo cambiar el proceso:

“es poco probable que el presidente Chávez reciba una influencia determinante de un pensador específico. Habría que analizar con mayor profundidad el campo heterogéneo de influencias que hay sobre los planteamientos de Chávez, más que suponer la influencia determinante de tesis teóricas planteadas por cualquier autor en particular" (Biardeau, 2009a, p. 349)

Dentro del amplio conjunto de signos manipulado por la Revolución Bolivariana, se proponen por entonces algunas redefiniciones y nuevos límites - pero sin romper con la narrativa lógica anterior. Por ende, el esfuerzo de elaborar una noción como el "socialismo bolivariano del siglo XXI", un socialismo venezolano y latinoamericano, incluyendo un Bolívar "proto- 
socialista” que, su hubiera vivido más algunas décadas, sería un introductor del socialismo utópico en América Latina (como de hecho lo fue en cierta medida Rodríguez). De ese modo, "la ideología bolivariana es el núcleo más duro, es el eje central del socialismo del siglo XXI en Venezuela, el socialismo que aquí estamos construyendo, la democracia socialista, el socialismo democrático, el nuevo socialismo”(Chávez, 2012, pp. 6-7). Chávez se declaró por entonces "radicalmente de izquierda, radicalmente socialista, radicalmente revolucionario, radicalmente antiimperialista, radicalmente comprometido con el pueblo venezolano y, especialmente, con los más humildes, con los excluidos de siempre, con los que más han sufrido, con los que sufren. Radicalmente bolivariano” (p. 27).

En ese sentido, una ligera mirada sobre los discursos de Chávez en ese periodo de proyectada transición demuestra que la yuxtaposición e hibridación se incrementaban, con sus significantes de todas las horas, pero ahora asociados de alguna manera a la nueva idea fuerza del socialismo - siempre en un proceso de agregación de sentidos, sin exclusiones. Algunos ejemplos:

Estamos construyendo el camino hacia el socialismo, colocando al ser humano en primer lugar (...). Este planeta se salva por el camino de un nuevo socialismo que aquí estamos comenzando a construir. (...) Hay que insistir en la creación de un nuevo modelo socialista, indoamericano, martiano, bolivariano, criollo, nuestro; un camino distinto a la destrucción del planeta (...). El Reino de Dios no es otro que el reino del socialismo verdadero, auténtico, un reino donde no haya clases sociales ni groseros privilegios (...). Nuestros pueblos originarios conservaron sus raíces socialistas. (...) Este proyecto nacional bolivariano va rumbo a un socialismo nuevo. No se trata de copiar nada, tenemos que inventar nuestro propio modelo de desarrollo. (Chávez, 2006; Biardeau, 2009b, pp. 95-97).

No hay efectivamente un cambio en los significantes utilizados - sin embargo, se daba entonces una aproximación al concepto de socialismo (aquí relativamente indefinido, en la medida que podía asociarse a casi todo). Se siguió con bolivarianismo, humanismo, latinoamericanismo (y antiimperialismo), cristianismo, ecologismo, desarrollo endógeno, nacionalismo, resistencia, comunismo y comunalismo de los pueblos originarios. Ideales ético-morales son articulados al socialismo, que se presenta como eminentemente social y cultural, no económico, lo que permitiría promover la propiedad privada "honesta”, basada en relaciones de trabajo “harmoniosas” (Maringoni, 2009, pp. 174-175). Chávez siguió refiriéndose.

A amplias influencias políticas que van desde Jesús pasando por Bolívar, Gramsci, Trotski y Mao llegando hasta Antonio Negri. Lo que a primera vista puede parecer un cóctel ideológico absurdo representa la amplitud de influencias políticas, sociales, culturales y hasta religiosas que nutren el bolivarianismo. Chávez no asume tanto el papel de dar una línea política sino más bien de abrir un marco 
político. De esta multiplicidad deriva el extraordinario potencial revolucionario del chavismo (Azzellini, 2007, s. p.).

El socialismo del siglo XXI en su expresión venezolana no constituyó mucho más entonces que "un concepto vago asociado a valores como la solidaridad, la fraternidad, la justicia, la libertad y la igualdad” (López Maya, 2008, p. 69), que recurrió al cristianismo, al marxismo, al bolivarianismo, al nacionalismo, entre muchos otros referentes. Eso podría ser de utilidad para producir nuevas articulaciones y constituir nuevas hegemonías. Pero se puede cuestionar si particularmente la noción de socialismo del siglo XXI en el caso venezolano podría prestarse a esa función. Y particularmente si esa nueva configuración de significantes (con la inclusión de un nuevo que atraviesa transversalmente a los demás) ha cambiado significados anteriores, volviéndolos eventualmente menos eficaces. Por ejemplo, hasta qué punto el nuevo "Bolívar socialista” siguió reconocible por las audiencias chavistas. En otras palabras, en qué medida el socialismo pudo combinarse con el culto a Bolívar "del pueblo" (para volver a la expresión de Carrera Damas) ${ }^{3}$. Probablemente eso no hizo sentido para todos, lo que podría explicar por una clave simbólica e inmaterial un poco de la creciente pérdida de hegemonía del chavismo - más allá de los duros y materiales datos de la realidad relacionados a la baja de la renta del petróleo en un país marcadamente rentista y a la pérdida innegablemente insustituible del talentoso líder de un proceso marcadamente personalista.

\section{Democracia en la Revolución Bolivariana y sus múltiples sentidos}

Democracia es uno de los conceptos y prácticas más polisémicos en el tiempo y en el espacio, yesa multiplicidad de sentidos se expresa en la Revolución Bolivariana. En ese caso, se debe antes de todo llamar la atención para la valoración de la soberanía popular (búsqueda por una “democracia verdadera” calcada en una expresión de la voluntad general), en clave rousseauniana, lo que se articula con el legado de Bolívar (como se mencionó, él mismo fuertemente influenciado por Rousseau) hecha por el chavismo.

El chavismo valoró ante todo el protagonismo popular, la iniciativa del soberano, del instituyente. Se pretendió realizar una "revolución democrática”, una "revolución por el voto". Como precisó Steve Ellner, “el modelo venezolano se basa en la tradición de la democracia radical que se remonta a Jean-Jacques Rousseau con su defensa del mandato de las mayorías y la participación directa en la toma de decisiones” (2012, p. 108). A partir de 2005, con la progresiva adhesión a un socialismo del siglo XXI, aumentó la insistencia en una democracia alternativa, llamada de muchas formas: directa, de base, protagónica, real, verdadera, plena. Ahora adoptando discursivamente un horizonte más volcado a la superación (aunque lejana) que a la complementación de la democracia representativa. Chávez afirmaba 
entonces que “ese es el eje central del socialismo en el campo de la política, democracia desde las bases, desde dentro, democracia plena” (Chávez, 2005, apudWilpert, 2009, p. 293). La base institucional del cambio serían los Consejos Comunales, instituciones de base microlocal definidas territorialmente, que deben formar comunas, que por su parte constituirán federaciones y confederaciones comunales, en una organización de base piramidal marcada por democracia directa en la base y delegación en los niveles superiores (Pereira da Silva, 2015). Es una concepción inserta en la larga tradición de los consejos, que remete a elementos identificables en el pensamiento socialista (estaba incluso en la lectura marxiana de la Comuna de París en La Guerra Civil en Francia), y fue defendida por muchos de los autores participacionistas de los años 1970 (por ejemplo, por C. B. Macpherson, 1981).

Se puede notar lo que constituye entonces, si no un cambio radical, por lo menos una significativa transición semántica en el discurso chavista que no puede pasar desapercibido: el tránsito de una "revolución democrática” a una "democracia revolucionaria”. "Hemos entrado en esa nueva etapa, la democracia revolucionaria, que no es lo mismo que decir, 'revolución democrática’, es otro concepto, es otra orientación [el primero tendría un sentido liberador, el segundo conservador], tomada en profundidad del pensamiento revolucionario de Simón Bolívar y de muchas otras corrientes universales, de todos los tiempos y de muchos lugares” (Chávez, 2005; Biardeau, 2009b, p. 80).

La “democracia revolucionaria” es asociada por veces a la “democracia socialista”, que sería la genuina, la verdadera. La consolidación de la democracia participativa y protagónica conduciría a la democracia socialista, forma política del "socialismo bolivariano". Se puede notar que participación y protagonismo popular son valores centrales mantenidos al largo del tiempo, pero ahora en asociación con la democracia socialista - del mismo modo que el bolivarianismo se mantiene, pero ahora asociado al socialismo. La democracia socialista sería sinónimo de poder popular. Se trata de un bricolaje de significados, en una transición que no fue suave, tampoco exenta de contradicciones. El proceso refundador venezolano presentó cambios (marcados por indefiniciones) que llevaron de una propuesta de refundación del Estado y de la República a un principio de ensayo de transición hacia una nueva sociedad, (in)definida como el socialismo del siglo XXI.

Al largo de ese intento inconcluso (y por ahora en franca degeneración), las nociones de democracia oficiales también vivenciaron cambios significativos como se mencionó. Chávez, que desde los años 1970 fomentaba movimientos militaristas que proponían el golpe de Estado - al final tentado sin éxito en 1992 -, después de amnistiado y libertado en 1994 defendió el boicot a las elecciones. Dejó ese posicionamiento para aceptar la participación institucional menos de dos años antes de su elección para la presidencia, y lo hizo de forma en cierta medida instrumental, pues consideraba podrida y engañosa la democracia vigente en su país. Sin embargo, al atacar las instituciones vigentes, propuso sustituirlas por nuevas institu- 
ciones democráticas. En los primeros años de gobierno, el proyecto de cambio apuntaba hacia una valoración de la participación expresada en la fórmula de la "democracia protagónica", volcada a un bien común, a una voluntad del pueblo, asociada a los valores propuestos por el bolivarianismo. En ese punto, las formas clásicas de representación deberían ser preservadas, y son de hecho reconocidas en la nueva Constitución.

Sin embargo, progresivamente se puede notar un cambio en esa combinación entre formas de representación y participación, hacia una mayor valorización de la segunda, concebida ahora en clave ligeramente distinta. Eso puede traducirse en la fórmula del "poder popular" y de una "democracia revolucionaria y socialista", como parte del diseño de una nueva "geometría del poder”. Chávez manifestó por entonces "más claramente tendencias a socavar las instituciones liberales” (López Maya, 2008, p. 69). Cuando se presenta la idea de una transición más profunda a una nueva sociedad y economía con el socialismo del siglo XXI, se puede notar que los promotores del concepto lo asocian siempre a la democracia, en contraposición al socialismo "burocrático”, "estatista” y “oligárquico” del siglo XX. Sin embargo, trabajan con nociones de democracia "participativa”, "directa”, “de base”, "protagónica”, "real”, "verdadera” - en un sentido más de superación que de complementariedad de la democracia representativa.

Mi sugerencia es que se puede entender "revolución democrática" como más democracia, democracia ampliada en los límites de la democracia liberal. Y por su parte “democracia revolucionaria” como más claramente otro tipo de democracia, en una ruptura simbólica con instituciones y métodos de la democracia de tipo liberal (¿esnecesario recordar que hubo y hay democracia más allá de las instituciones liberales?). Los Consejos Comunales podrían ser la base y la expresión concreta de esas ideas, sin embargo, se presentan como un proyecto en crisis y posible agotamiento -como además todo el proceso de cambio, ahora en abierta degeneración.

\section{Conclusión: Venezuela como un caso ejemplar de recepción y producción de ideas de izquierda en la periferia}

Después de ese paso por las ideas centrales de la Revolución Bolivariana, propongo comprender ese proceso en un contexto ampliado, como expresión de algunos patrones observables en la recepción y producción de ideas y conceptos por parte de las izquierdas periféricas. Del mismo modo que el bolivarianismo para el chavismo, es notable en distintas experiencias de izquierda la presencia de ideas que son presentadas como formulaciones locales, nacionales, originarias. Son creaciones originales y a la vez adaptaciones, aclimataciones, hibridaciones a partir de la recepción selectiva de las ideas de izquierda producidas inicialmente en los países centrales. Esas nuevas formulaciones son el alimento para procesos de tradicionalización y nacionalización de las izquierdas, o sea, intentos de inserción de esas izquierdas en la Historia y en la sociedad donde se ubi- 
can. Son hechas articulaciones con lo que sería la identidad nacional, intersecciones con mitologías político-sociales y pretensas herencias del pasado local, asociaciones al legado de personajes históricos que vuelven fuente de culto.

De esa manera, se remite muchas veces a un pasado romantizado, "épocas de oro" que podrían servir de base a la nueva sociedad que se sueña construir; o a "héroes" y episodios idealizados de la narrativa histórica local, cuyo legado y vigencia constituirían la base para los cambios societarios. Carrera Damas, refiriéndose al bolivarianismo, considera

"Difícil decir qué infunde más ánimo e impulsa más a un pueblo, si la persecución de una alta meta o la evocación de un pasado de grandeza y esplendor. Pero sí es posible afirmar que el más efectivo tónico está compuesto por una armónica combinación de esos ingredientes, pues si el señalamiento de un objetivo grande y hermoso incita a marchar hacia él, la evocación de un pasado no menos grande y hermoso constituye elocuente y convincente garantía de que es posible alcanzarlo, e incluso de que indefectiblemente se le alcanzará, y los pasos vacilantes adquirirán aplomo, los hombres desalentados se tornarán optimistas, y las consciencias desesperadas recuperarán la fe. Es la escueta fórmula, plena de sentido histórico: seremos porque hemos sido" (2013, p. 210, cursiva en el original).

Se puede hablar de intentos de nacionalización del pensamiento en las periferias de un modo general, lo que hay en todas las familias intelectuales y políticas. Pero las izquierdas, de formación más reciente y al largo de los sectores dirigentes e intelectuales tradicionales, probablemente necesitan con aún más intensidad y urgencia presentarse como parte constitutiva de la sociedad que pretenden gobernar y cambiar; no como algo exótico, impuesto desde fuera, asociado a modelos foráneos (como son insistentemente presentadas por sus oponentes de distintos cuadrantes). En ese proceso, elementos identitarios de esas sociedades y de sus narrativas históricas pasan por relecturas (con selecciones, adaptaciones y nuevos énfasis) de modo a volverse más afines a aquellas izquierdas.

La articulación con la historia nacional, en especial con el legado de personajes-clave de esa historia, es insistente. Momentos históricos fundadores de la nacionalidad, o entendidos como centrales para el surgimiento y consolidación posterior del país en su configuración moderna, son comprendidos desde la izquierda como llenos de ideales libertarios, comunitarios, antiimperialistas, democráticos, proto-socialistas. Los ejemplos en ese sentido son muchos. Podrían ser entendidos de esa forma, más allá del uso de Bolívar por el chavismo, y pensando sólo en América Latina: la apropiación de José Martí hecha por la Revolución Cubana; de Juan Perón y particularmente de Evita por el kirchnerismo; de Eloy Alfaro y del alfarismo por Rafael Correa; de José Artigas y el artiguismo por sectores del Frente Amplio; de la tradición blanca por José Mujica; entre otros ejemplos. 
En especial las corrientes latinoamericanas nacional-populares recurren a ese tipo de articulación - incluso los revolucionarios cubanos, nacional-populares en su origen ${ }^{4}$. La reinvención progresista de historias nacionales y del legado de personajes y episodios es una característica común a todas esas propuestas. Muchas veces esa búsqueda en la periferia por una relectura desde la izquierda de los conceptos de “nación” y de “pueblo" es entendida por críticos de la academia y/o de la política en la clave acusatoria del "populismo", y son más precisamente aquellos dos conceptos los elementos principales a generar o justificar la reacción negativa al llamado “populismo”. En resumen, los adversarios académicos/políticos de esas formulaciones exhiben notable dificultad para evaluar de forma distinta cómo esas dos ideas - nación y pueblo - pueden manifestarse en clave progresista y creativa en la periferia de la modernidad global, alimentando proyectos transformadores e igualitarios.

Los procesos aquí mencionados muchas veces constituyen "invenciones de tradiciones”, en el sentido presentado por Hobsbawm y Ranger (2012). Son formalizadas, repetidas y hasta institucionalizadas por Estados, gobiernos y grupos políticos, constituyendo formas de legitimación, cohesión social e inculcación de valores. “Por ‘tradición inventada’ se entiende un conjunto de prácticas, normalmente reguladas por reglas tácita o abiertamente aceptadas; tales prácticas, de naturaleza ritual o simbólica, visan inculcar ciertos valores y normas de conducta por medio de la repetición, lo que implica, automáticamente, una continuidad con relación al pasado" (Hobsbawm, 2012, p. 12). Según Hobsbawm,
"se inventan nuevas tradiciones cuando ocurren cambios suficien- temente amplios y rápidos tanto del lado de la demanda cuanto de la oferta (...). Eso implica, al contrario de la concepción divulgada por el liberalismo del siglo XIX y por la teoría de la ‘modernización’, que es más reciente, la idea que tales formalizaciones no son restrictas a las llamadas sociedades ‘tradicionales’, pero también ocurren, bajo las más diversas formas, en las sociedades 'modernas”’(Ibíd., p. 16).

En el sentido señalado por el autor, esas prácticas vuelven más comunes en momentos de cambios acelerados, lo que ocurrió efectivamente en la fundación de nuevos Estados como en la descolonización africana y asiática, o en momentos de "refundación” como los recientes procesos refundadores de Venezuela, Bolivia y Ecuador (Pereira da Silva, 2015). En ese sentido, Edward Said (2011) destacó:

“el poder de movilización de los imágenes y tradiciones presentadas y su carácter ficticio o, por lo menos, fantasiosamente teñido de colores románticos (...). En los Estados nacionales postcoloniales es evidente la flexibilidad de esencias tales como el espíritu celta, la negritud o el islamismo” (Said, 2011, p. 53).

Como en la mención de Said, la noción de “romanticismo” eventualmente aparece al referirse a ideas que buscan referencias en un pasado pre- 
moderno. Y para muchos autores, hablando desde ciertas tradiciones modernizantes y/o marxistas, eso será comprendido en clave negativa, incluso de acusación (y es interesante notar que un autor como Said en la cita anterior pueda hacer lo mismo). Sin embargo, la lectura de la obra de Michael Löwy y Robert Sayre, editada en español en 2008 bajo el título deRebelión y melancolía: el romanticismo a contracorriente de la modernidad, puede alumbrar la cuestión, ofreciendo una perspectiva más interesante. Los autores defienden que el romanticismo puede ser entendido no como una corriente artístico-literaria de fines del siglo XVIII y principio del XIX (como se acostumbró hacer), pero como una visión de mundo, un modo de entender el mundo moderno que se mantiene hasta hoy, casi como una antítesis de la modernidad (como Marx ya parecía sugerir en sus Grundrisse). De ese modo, el romanticismo puede ser entendido como una crítica a la modernidad surgida desde la modernidad, desde su interior. Eso lleva los autores al cuestionamiento de la visión del romanticismo como algo pasadista, reaccionario, destacando que él muchas veces apunta hacia una perspectiva de futuro, por veces presentándose incluso como revolucionario y de izquierda. Se trataría en ese caso entonces no de un retorno al pasado, pero de buscar en el pasado elementos para la construcción de un futuro alternativo - en la medida que ese pasado es percibido como el momento de realización plena del individuo, de la nacionalidad, de la comunidad. Si algo pasó, puede pasar otra vez en nuevas bases (el "seremos porque hemos sido" mencionado por Carrera Damas).

Si esas izquierdas en sus procesos de nacionalización apelan a un pasado (más o menos mitificado), se trata de apropiarse y transformar elementos de un pasado que es parte integrante del presente. En los términos de ReinhartKoselleck (1993) de un "pasado actual” - de lo contrario no haría sentido realizar tal apropiación -, de modo a fortalecer un proyecto de futuro. Se trata de conectarse y empezar a integrar (no ser foráneo a) un determinado "espacio de experiencia”, para producir un nuevo "horizonte de expectativas", un nuevo "futuro presente". Mi sugerencia es que el énfasis de esas izquierdas sigue siendo dirigida hacia el futuro, a la construcción de una nueva sociedad, a un pretenso "progreso", a la profundización del proyecto de la modernidad - pero buscando sortear etapas, evitar reproducir elementos del desarrollo capitalista, romper con posiciones periféricas en el sistema mundial. En ese sentido, no dejan de estar insertas en la modernidad global - aunque se pueda sugerir que profundizan su pluralidad, multiplicidad, sus alternativas internas, y al fin y al cabo desarrollan una relación tensa con ella. Aunque se insista en la supervivencia de elementos comunales, de valores tradicionales igualitarios o en la vigencia de personajes del pasado, no se considera que sociedades y tiempos antiguos puedan ser reconstituidos o que procesos históricos deban repetirse. La apuesta es que eses fragmentos sobrevivientes y personajes y valores obyectos de culto sean los potencializadores de una sociedad nueva, de una nueva era, no de un regreso. Esos fragmentos llenan de contenido un nuevo horizonte de expectativas propuesto, atravesado en gran medida por un sentido de progreso característico de las filosofías de la historia asociadas a la modernidad. 
Hay, por ende, una separación entre espacio de experiencia y horizonte de expectativas, que Koselleck señala como característico de la modernidad. Pero esa separación no es un abismo, hay conexiones y continuidades entre uno y otro, hay diversas combinaciones e hibridaciones. Se trata en ese sentido de "revolución" más en el sentido propiamente moderno del concepto, definido por Koselleck como una aceleración rumbo al futuro; no tanto en el sentido antiguo (una vuelta del puntero del reloj, eterno retorno en una concepción de tiempo $\operatorname{circular}^{5}$ ), que sin embargo no se pierde totalmente. Aquel autor señalaba categóricamente que revolución en sentido moderno tendría obligadamente que apuntar sólo hacia el futuro u no sería revolución. Mi sugerencia es que la cuestión debe ponerse en clave bien más compleja, particularmente en la periferia global, y retomando la reflexión de Löwy e Sayre, se puede afirmar que sin "nostalgia del pasado, no puede existir sueño de futuro auténtico. En ese sentido la utopía será romántica o no será” (2015, p. 269).

Son revoluciones entonces que no se legitiman sólo en el futuro, en la búsqueda de la nueva sociedad y del "hombre nuevo", pero también en el pasado. Volviendo a las dos nociones de legitimación del poder basadas en la Historia de las que hablaba Norberto Bobbio (2006), se puede decir que esas izquierdas siguen trabajando en la clave de la legitimación basada en la "historia futura". Sin embargo, agregan elementos asociados a la legitimación por medio de la "historia pasada" - lo que no debe comprenderse como contradictorio, como parecía sugerir Bobbio, sino mientras algo que puede ser perfectamente complementar. En el límite, se trata de comprender la modernidad y sus tiempos como algo que no es monolítico. Y de reconocer la existencia, en particular en la periferia global, de "tiempos heterogéneos”, como en la formulación de ParthaChatterjee (2008) desarrollada para comprender alternativamente la constitución de naciones.

Se tratan entonces de fenómenos de reinvención de la historia en clave progresista, por parte de izquierdas que se presentan como eminentemente nacionales, locales, representantes de valores autóctonos, cuando no mientras fundadoras o refundadoras de la misma nacionalidad. Se realiza así un doble proceso (sólo en apariencia contradictorio): de rompimiento con el pasado, por eso de creación; pero que es también una refundación, que se reconecta y vuelve en cierto sentido a un pasado. Más precisamente lo recría.

En Venezuela, a partir de 2005, se empezó a ensayar una experimentación que podría significar - aunque en potencia - el diseño de un nuevo modelo (en teoría) democrático, basado en una larga tradición de consejos y en una formulación de lo que sería el socialismo para el siglo XXI. Una tradición no exactamente local, sino universalista y fuertemente modernista. Eso podría explicar parcialmente los límites del experimento - empezando por la derrota chavista en el referendo del 2007 para hacer reformas constitucionales en clave socialista. En perspectiva, el significante bolivarianismo tuvo probablemente más fortuna que el socialismo del siglo XXI. O sea, hay espacio para importación y adaptación de ideas y conceptos de otras par- 
tes. Sin embargo, eso tiene que obedecer a dados parámetros y límites locales - cambiantes pero existentes. Las ideas con origen o por lo menos fuertes raíces locales tienen más posibilidades de éxito. La introducción de nuevos significantes y la condensación de significados en ellos no son fenómenos tan simples. Se puede sugerir en ese caso que la introducción sin mucha base y preparación de ideas como el socialismo y la democracia revolucionaria puede haber producido algún "cortocircuito" en la comunicación con las bases bolivarianas, encontrando ciertos límites simbólicos ofrecidos por la cultura política venezolana vigente - sin mencionar evidentes límites materiales. Una decidida retomada del bolivarianismo y del nacional-popular mediados por un culto mesiánico a Chávez podrían (re)establecer conexiones más hondas con las bases populares venezolanas. Sin embargo, el proyecto político chavista parece en ese momento agotado, sin capacidad de reaccionar (por lo menos en los límites democráticos) a su peor crisis y reconstituir mayorías. Eso explica en parte el “empate catastrófico" vivenciado por Venezuela en ese exacto momento, de muy difícil resolución - y explica el presente cierre autoritario del régimen.

Las propuestas de la Revolución Bolivariana se quedaron entonces a medio camino de una ruptura más radical. A los intentos de buscar nuevas formas de integración regional (como el ALBA), a los experimentos de autogestión, a los proyectos de "desarrollo endógeno" o a las nuevas formas de democracia participativa (como los Consejos Comunales) corresponden las formulaciones novedosas centradas en el bolivarianismo, en el socialismo del siglo XXI y en los nuevos significados de la democracia. Esas formulaciones se quedaron en el medio del camino de la crítica a la modernidad capitalista, sin llegar al punto de su superación en la dirección de nuevas formas de sociabilidad. Sin embargo, esa Revolución dejónuevos elementos (y experimentos) para el rico cuerpo de ideas de las periferias - a la espera de más investigaciones y de reconocimiento. 


\section{Notas}

${ }^{1}$ Para más informaciones, conferir Ferreira (2006).

${ }^{2} \mathrm{Y}$ aquí se debe recordar el proyecto de integración (ahora en crisis) de la Alianza Bolivariana para los Pueblos de Nuestra América, el ALBA.

${ }^{3}$ Lo mismo sirve para el "Cristo socialista". El cristianismo en clave progresista tributario de la Teología de la Liberación - siempre estuvo presente en las reflexiones de Chávez. Desde la inclusión de elementos socialistas se buscó asociar las dos tradiciones. Más allá de las múltiples referencias explícitas, Ordoñez (2010) remite a elementos místicos, milenaristas y organicistas, integrantes de las narrativas cristianas y fuertemente arraigadas en los discursos de Chávez (y también de Rafael Correa).

${ }^{4}$ Por ejemplo, estudiar el proficuo debate que se desarrolla desde los años 1950 acerca de la posibilidad de un "peronismo de izquierda" o de una "izquierda peronista" puede ser esclarecedor acerca de la génesis, potencialidad y límites de ese tipo de formulación - lo que será realizado en trabajos futuros.

${ }^{5}$ El eterno retorno nietzscheano, curiosamente tan mencionado en los discursos de Chávez. 


\section{Bibliografía}

Azzellini, D.(2007). La Revolución Bolivariana: “o inventamos o erramos”. Claves para leer el proceso de transformación social venezolano. Herramienta36.

Biardeau, J. (2009a). ¿El proceso de transición hacia el nuevo socialismo del siglo XXI? Un debate que apenas comienza. En M. Ayala y P. Quintero (comps.). Diez años de revolución en Venezuela: historia, balance y perspectivas (1999-2009). Ituzaingó, Argentina: Maipue.

(2009b). Del árbol de las tres raíces al "socialismo bolivariano del siglo XXI”. ¿Una nueva narrativa ideológica de la emancipación?Revista Venezolana de Economía y Ciencias Sociales $15(1)$

Bobbio, N. (2006). Estado, gobierno y sociedad. Por una teoría general de la política. México DF, México: Fondo de Cultura Económica.

Carrera, G. (2013). El culto a Bolívar. Esbozo para un estudio de la historia de las ideas en Venezuela. Caracas, Venezuela: Alfa.

Chaterjee, P. (2008). La nación en tiempo heterogéneo y otros estudios subalternos. Buenos Aires, Argentina: Siglo XXI.

Chávez, H. (2012). Radicalmente bolivariano, antiimperialista y revolucionario. Caracas, Venezuela: Correo del Orinoco.

(2007). El Libro Azul. Caracas, Venezuela: Ministerio del Poder Popular para la Comunicación e Información.

Devés-Valdés, E. (2017). Pensamiento Periférico. Asia, África, América Latina, Eurasia y más. Una tesis interpretativa global. Santiago, Chile: Ariadna Ediciones.

DieterichSteffan, H. (2002). El Socialismo del Siglo XXI. noblogs.org/oldgal/ 737/SocialismoXXI.pdf

, Franco, R. (2012). The scientific-philosophical foundations of twenty-first-century socialism. International CriticalThought 2 (1).

Ellner, S. (2012). El modelo de la democracia social radical en Venezuela: innovaciones y limitaciones. Cuadernosdel CENDES 29 (79).

Ferreira, C. (2006). Ideologia bolivariana: as apropriações do legado de Simón Bolívar em uma experiência de povo em armas na Venezuela. O caso da Guerra Federal (1858-1863). (Tesis de Maestría), UFRGS, Porto Alegre, Brasil. 
Figueiredo, A. (2013). Ecos do Libertador: Simón Bolívar no discurso de Hugo Chávez. São Paulo, Brasil: Annablume, Prolam.

Gramsci, A. (2001). Cuadernos de la cárcel. México DF, México: Ediciones ERA-Universidad Autónoma de Puebla.

Hobsbawm, E. yRanger, T. (orgs.) (2012). A invenção das tradições. Rio de Janeiro, Brasil: Nova Fronteira.

(2012). Introdução: a invenção das tradições. EnE. Hobsbawm yT. Ranger (orgs.). A invenção das tradições. Rio de Janeiro, Brasil: Nova Fronteira.

Koselleck, R. (1993). Futuro pasado: para una semántica de lostiempos históricos. Barcelona, España: Paidós.

Laclau, E. (2009). La razón populista. Buenos Aires, Argentina: Fondo de Cultura Económica.

López Maya, M. (2008). Venezuela: Hugo Chávez y el bolivarianismo. Revista Venezolana de Economía y Ciencias Sociales 14 (3).

Löwy, M., Sayre, R. (2015). Revolta e melancolia: o romantismo na contracorrente da modernidade. São Paulo, Brasil: Boitempo.

Macpherson, C. (1981). La democracia liberal y su época. Madrid, España: Alianza Editorial.

Maringoni, G. (2009). A revolução venezuelana. São Paulo, Brasil: Ed. UNESP.

Ordoñez, P. P. (2010). El Presidente Rafael Correa y su política de redención. Ecuador Debate80.

Pereira Almao, V. (2003). Movimiento V República (MVR). EnM. Alcántara y F. Freidenberg (coords.). Partidos políticos de América Latina. Países Andinos. México DF, México: Fondo de Cultura Económica, Instituto Federal Electoral.

Pereira da Silva, F. (2015). Democracias errantes. Reflexões sobre experiências participativas na América Latina. Rio de Janeiro, Brasil: Ponteio.

(2011). Vitórias na crise: trajetórias das esquerdas latino-americanas contemporâneas. Rio de Janeiro, Brasil: Ponteio.

Pidival, F. (1977). Bolívar. Pensamiento precursor delantiimperialismo. La Habana, Cuba: Ediciones Casa de las Américas. 
Rodríguez, S. (2004). Inventamos o erramos. Caracas, Venezuela: Monte Ávila.

Said, E. W. (2011). Cultura e imperialismo. São Paulo, Brasil: Companhia das Letras.

Santos, B. S. (2010). Para além do pensamento abissal: das linhas globais a uma ecologia de saberes. En Santos, B. S. y Meneses, M. P. (orgs.). Epistemologias do Sul. São Paulo, Brasil: Cortez.

Seabra, R. L. yPereira da Silva, F. (2012). Sugerencias teóricas para un abordaje de la vía bolivariana. Revista Historia III (3).

Wilpert, G. (2009). La transformación en Venezuela. Hacia el Socialismo del Siglo XXI. Caracas, Venezuela: Monte Ávila.

Zúquete, J. P. (2008). The missionary politics of Hugo Chávez.Latin American Politics and Society 50(1). 